\title{
Preliminary Report on the Indoor Electromagnetic Radiation in a Municipality of Western P.R. China: Up-to-Now Still within the Range
}

\author{
Tingting Fu, Yu Chen, Lingli Han, Qizhong Qin
}

The School of Public Health, Chongqing Medical University, Chongqing, China.

Email: lucychenyu2000@yahoo.com.cn

Received February 21 ${ }^{\text {st }}, 2012$; revised April 10 ${ }^{\text {th }}, 2012$; accepted April 20 $0^{\text {th }}, 2012$

\begin{abstract}
Objective: This study is designed to measure the current level of Indoor Electromagnetic Radiation (IER) in Chongqing, a municipality of western P.R. China, on which further epidemiological investigation on the relation between the level of IER and certain health effects could be based. Methods: 118 Households in 4 urban residential districts in Chongqing were randomly selected. The IER intensity was measured in each household's living room at different frequencies under three different conditions. Results: The average electric field intensity measured at the frequency range of $1 \mathrm{MHz}-40 \mathrm{GHz}$ was within the guidelines set by the International Commission on Non Ionizing Radiation Protection (ICNIRP). The electromagnetic field intensity measured at other frequencies were at the lowest range of the acceptable values. The average electric field intensity at the frequency range of $5 \mathrm{~Hz}-1 \mathrm{kHz}$ was higher at a standing posture than at a sitting posture with domestic appliances turned off in both cases $(\mathrm{P}<0.01)$. Conclusion: The indoor electromagnetic radiation in Chongqing currently is still within the recommended public exposure limit set by ICNIRP.
\end{abstract}

Keywords: Household Appliances; Indoor Electromagnetic Radiation; Measurement

\section{Introduction}

High technology is now accessible to many consumers in the form of cell phones, computers, TV and other popular electronic appliances. The ubiquitous availability of these appliances has provided people with unprecedented convenience. However, these modern conveniences may have exposed the consumers to some possible negative influences [1-3]. According to some recent studies, electromagnetic radiation produced by various high-tech office equipment and household appliances has become another source of indoor environment pollutions in addition to air pollution, radioactive pollution and noise pollution. Recently some researches have suggested that electromagnetic radiation may cause health problems to humans $[4,5]$. Therefore from a public health perspective, caution is always preferable to subsequent costly remedies [6]. The main purpose of this study is to evaluate the levels and characteristics of indoor residential environmental electromagnetic radiation in a modern living environment. Specifically the study will analyze the additional impact of household appliances on the average electromagnetic radiation field intensity, and examine the possible correlation between indoor electromagnetic radiation intensity and the total power output of household appliances, thus providing a reference for monitoring and evaluation of and developing safety standards for indoor electromagnetic radiation.

\section{Materials and Methods}

\subsection{Measuring Equipment}

The measurements were taken by an electromagnetic radiation integrative Field Strength Analyzer from the Italian PMM company (PMM 8053B) and a spectrum analyzer from the German SPECTRAN Series (HF-2025E). PMM 8053B is an isotropic, broadband Field Strength Analyzer. In this measurement we selected 8 measuring probes with different frequency ranges for use in conjunction with the host.

\subsection{Measurement Methods}

4 residential communities were randomly selected (marked $\mathrm{A}, \mathrm{B}, \mathrm{C}$ and $\mathrm{D}$ ) in Chongqing. Community $\mathrm{A}$ and $\mathrm{B}$ is located in urban area whereas $\mathrm{C}$ and $\mathrm{D}$ is in suburban area. $28,32,25$, and 33 households were randomly selected in district A, B, C and D respectively. Since the long-term exposure to indoor electromagnetic radiation is our main concern, and a pilot investigation showed that 
the people stay most of their time in bedroom, followed by living room and kitchen. Therefore the living room of each household was selected as the measuring site. Three kinds of states in the measurement were: State I: probe took place at 1.7 meters above ground where people were in the standing posture, with indoor electric appliances (TV, lights, air conditioner, microwave oven, personal computer) turned off; State II: probe took place at 1.7 meters above ground where people were in standing posture, with indoor electric appliances turned on; State III: at 1.5 meters above ground where people were in the sitting posture, with indoor electric appliances turned on. Electric fields were measured in volts per meter $(\mathrm{V} / \mathrm{m})$. Magnetic fields were measured by magnetic flux intensity in micro-tesla $(\mu \mathrm{T})$ and power flux density was expressed in $\mathrm{nW} / \mathrm{m}^{2}$.

\subsection{Statistical Analysis Methods}

Statistical software SAS 8.0 (SAS Institute, Inc., Cary, NC) was employed to conduct analysis of variance (ANOVA) and linear correlation analysis. Descriptive data was given as mean \pm standard deviation (SD). Normal distributions and box-cox transformation were conducted to test the measuring data. Homogeneity-ofvariances were tested by Levene test. Statistical signifycance was defined as $\mathrm{P}<0.05$.

\section{Results}

\subsection{Results of Indoor Electromagnetic Radiation Intensity}

Under the current environmental electromagnetic radiation safety standards in China: Regulations for electromagnetic radiation protection (GB8702-88) and Hygienic standard for environmental electromagnetic wave (GB 9175-88), there are no safety standards for electromagnetic wave at frequency range below $100 \mathrm{kHz}$. Therefore, the Time-varying electric, magnetic and electromagnetic field exposure limit guidelines from the International Commission on Non-Ionizing Radiation Protection (ICNIRP) recommended by the WHO was adopted to analyze the results of this measurement. Comparing the results to the general public exposure limits established by the time-varying electric and mag- netic fields in the ICNIRP guidelines, it was found that none of the measured values exceeded the limit set in the ICNIRP guidelines in the corresponding frequency ranges.

As can be seen in Table 1, the values of electric field intensities and magnetic flux intensities at the frequency range of $5 \mathrm{~Hz}-100 \mathrm{kHz}$ and $1 \mathrm{kHz}-100 \mathrm{kHz}$, plus the power flux density at frequency range of $700 \mathrm{MHz}-2.5$ $\mathrm{GHz}$ obviously changed while the values of the other frequency ranges were relatively stable.
The average electric field intensities were measured at six frequency ranges and the values of which were showed in three conditions in Figure 1. The highest average electric field intensity at frequency range from 1 $\mathrm{MHz}$ to $40 \mathrm{GHz}$ in three types of state were $17.171 \mathrm{~V} / \mathrm{m}$, $17.176 \mathrm{~V} / \mathrm{m}$ and $17.173 \mathrm{~V} / \mathrm{m}$ respectively, which were close to the limit in the CNIRP guidelines $\left(87 / \mathrm{f}^{1 / 2}, \mathrm{f}^{\prime} \mathrm{s}\right.$ unit is $\mathrm{MHz}$ ). The average electric field intensity at frequency range from $5 \mathrm{~Hz}$ to $1 \mathrm{kHz}$ in state II was 16.797 $\mathrm{V} / \mathrm{m}$. The average electric field intensities at frequency range from $1 \mathrm{kHz}$ to $100 \mathrm{kHz}$ were the lowest; the values

Table 1. Values of frequency range of $5 \mathrm{~Hz}-1 \mathrm{kHz}, 1 \mathrm{kHz}$ $100 \mathrm{kHz}$ and $700 \mathrm{MHz}-2.5 \mathrm{GHz}$.

\begin{tabular}{|c|c|c|c|c|}
\hline $\begin{array}{c}\text { Variable } \\
\text { (frequency, Unit) }\end{array}$ & state & Mean $\pm \mathrm{SD}^{\#}$ & Min. $\sim$ Max. ${ }^{*}$ & Median \\
\hline \multirow{4}{*}{$\begin{array}{c}\mathrm{E} \\
(5 \mathrm{~Hz}-1 \mathrm{kHz}, \mathrm{V} / \mathrm{m})\end{array}$} & I & $2.63 \pm 4.60$ & $0.07-17.90$ & 0.96 \\
\hline & II & $16.80 \pm 15.62^{\mathrm{a}}$ & $0.68-77.96$ & 11.90 \\
\hline & III & $3.26 \pm 5.19^{\mathrm{b}}$ & $0.05-24.06$ & 2.14 \\
\hline & I & $0.04 \pm 0.08$ & $0.00-0.36$ & 0.01 \\
\hline \multirow[t]{2}{*}{$\begin{array}{c}\mathrm{B} \\
(5 \mathrm{~Hz}-1 \mathrm{kHz}, \mu \mathrm{T})\end{array}$} & II & $0.06 \pm 0.08$ & $0.01-0.32$ & 0.02 \\
\hline & III & $0.05 \pm 0.09$ & $0.01-0.44$ & 0.02 \\
\hline \multirow{3}{*}{$\begin{array}{c}\mathrm{E} \\
(1 \mathrm{kHz}-100 \mathrm{kHz}, \\
\mathrm{V} / \mathrm{m})\end{array}$} & I & $0.21 \pm 0.03$ & $0.11-0.27$ & 0.21 \\
\hline & II & $0.36 \pm 0.33^{\mathrm{a}}$ & $0.15-1.96$ & 0.24 \\
\hline & III & $0.22 \pm 0.04$ & $0.13-0.43$ & 0.22 \\
\hline \multirow{3}{*}{$\begin{array}{c}\mathrm{B} \\
(1 \mathrm{kHz}-100 \mathrm{kHz}, \\
\mu \mathrm{T})\end{array}$} & I & $0.05 \pm 0.00$ & $0.03-0.06$ & 0.05 \\
\hline & II & $0.05 \pm 0.00$ & $0.04-0.06$ & 0.05 \\
\hline & III & $0.05 \pm 0.00$ & $0.03-0.06$ & 0.05 \\
\hline \multirow{3}{*}{$\begin{array}{c}\mathrm{S} \\
(700 \mathrm{MHz}-2.5 \mathrm{GHz}, \\
\left.\mathrm{nW} / \mathrm{m}^{2}\right)\end{array}$} & I & $216.07 \pm 324.19$ & $0.07-1570.00$ & 79.19 \\
\hline & II & $212.85 \pm 420.64$ & $0.57-2750.00$ & 76.78 \\
\hline & III & $722.47 \pm 3265.13$ & $0.68-23230.00$ & 57.18 \\
\hline
\end{tabular}

*Minimum maximum values. "Mean \pm Standard Deviation. ${ }^{\text {ab }}$ means of statistical significance compared to state I and II, respectively. E, B and S stands for electric field intensity, magnetic field intensity and power density, respectively.

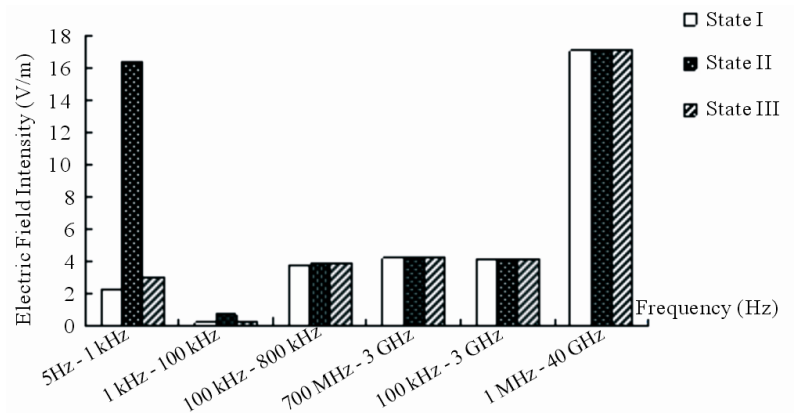

Figure 1. Average electric field intensity $(\mathrm{V} / \mathrm{m})$ at different frequencies under three states. 
of other frequency ranges were no more than $5 \mathrm{~V} / \mathrm{m}$.

\subsection{The Analysis of Indoor Electromagnetic Radiation Under the Three States}

The measurement and analysis of the indoor average electric field intensity and average magnetic flux intensity were carried out in three conditions. As shown in Table 2, the differences between the values of electric field intensity in state I and state II at the same frequency range, and the differences of the values at the frequency range of $5 \mathrm{~Hz}-1 \mathrm{kHz}(P<0.05)$ and $1 \mathrm{kHz}-100 \mathrm{kHz}(P$ $<0.01)$ were statistically significant. In addition, combining the results in Table 1, we observed that at the aforementioned frequency ranges, the values of the average electric field intensity in state II were much higher than that in state I. It means that when people were in the same standing posture, the average values of electric field intensity measured with indoor electric appliances turned on were much higher than that measured with indoor electric appliances turned off.

A comparison of all the average electric field intensity between state II and state III illustrated that the differences at the frequency range of $5 \mathrm{~Hz}$ to $1 \mathrm{kHz}(P<0.01)$ were the only significant ones. Likewise combining the results in Table 1 shows that the average electric field intensity as measured in a standing posture was much greater than that measured in a sitting posture when the indoor electric appliances was turned on. It became clear in the investigation that people in a standing posture always stood between the TV and the sofa, and as such people's head were relatively closer to the sources of the electromagnetic radiation, such as TV or electric light above the head, in contrast to the situation in which peo-

Table 2. Inter-comparisons of each frequency range among the three states.

\begin{tabular}{llll}
\hline Variable (Frequency, Unit) & Sate I - II & Sate II - III Sate I - III \\
\hline E $(5 \mathrm{~Hz}-1 \mathrm{kHz}, \mathrm{V} / \mathrm{m})$ & $P=0.000^{*}$ & $P=0.001^{*}$ & $P=0.631$ \\
$\mathrm{~B}(5 \mathrm{~Hz}-1 \mathrm{kHz}, \mu \mathrm{T})$ & $P=0.459$ & $P=0.753$ & $P=0.539$ \\
E $(1 \mathrm{kHz}-100 \mathrm{kHz}, \mathrm{V} / \mathrm{m})$ & $P=0.037^{*}$ & $P=0.065$ & $P=0.755$ \\
$\mathrm{~B}(1 \mathrm{kHz}-100 \mathrm{kHz}, \mu \mathrm{T})$ & $P=1.000$ & $P=0.302$ & $P=0.827$ \\
E $(100 \mathrm{kHz}-800 \mathrm{MHz}, \mathrm{V} / \mathrm{m})$ & $P=0.552$ & $P=0.768$ & $P=0.368$ \\
E $(700 \mathrm{MHz}-3 \mathrm{GHz}, \mathrm{V} / \mathrm{m})$ & $P=0.388$ & $P=0.845$ & $P=0.684$ \\
E $(100 \mathrm{kHz}-3 \mathrm{GHz}, \mathrm{V} / \mathrm{m})$ & $P=1.000$ & $P=1.000$ & $P=1.000$ \\
E $(1 \mathrm{MHz}-40 \mathrm{GHz}, \mathrm{V} / \mathrm{m})$ & $P=0.465$ & $P=0.519$ & $P=0.493$ \\
$\mathrm{~S}\left(700 \mathrm{MHz}-2.5 \mathrm{GHz}, \mathrm{nW} / \mathrm{m}^{2}\right)$ & $P=0.979$ & $P=0.349$ & $P=0.817$ \\
\hline
\end{tabular}

*Differences are of statistical significance; E, B and S stands for electric filed intensity, magnetic flux density and power density, respectively. ple were in sitting posture. Also the results described above confirmed that the intensity of the electromagnetic waves decreases significantly with increasing distance, a characteristic of electromagnetic waves [7].

\subsection{Relation between Total Power of Electric Appliances and Field Intensity at Frequency Range from $5 \mathrm{~Hz}$ to $1 \mathrm{kHz}$}

The power of all sorts of household electrical appliances, $50 \mathrm{~Hz} / 60 \mathrm{~Hz}$, is within the frequency range $5 \mathrm{~Hz}$ to 1 $\mathrm{kHz}$. Figure 2 shows a linear correlation between the average electric field intensity of the 118 households (measured in a standing posture) and the total power of turned-on electric appliances $(r=0.07)$. Figure 3 shows the average electric field intensity versus total power measurements in a sitting posture $(r=0.047)$. Figure 4 shows the linear correlation between the average magnetic flux intensity of the 118 households (as measured in a standing posture) and the total power of turned-on electric appliances $(r=0.072)$. Figure 5 shows the average magnetic flux intensity versus total power measured in a sitting posture $(r=0.067)$.

\section{Discussion}

Indoor electromagnetic radiation is mainly produced by spatial spread and transmission emitted from conductors. Electromagnetic waves travel on multiple paths from senders to receivers and can be absorbed, reflected or shielded by reinforced concrete walls or other building materials, thus rendering windows, balconies or other open places the main path by which the outdoor electromagnetic radiation leaks into the house [8]. Therefore, there are two main sources of indoor electromagnetic radiation pollution. One is outdoor electromagnetic radiation leakage whose sources is widespread but mainly at radio frequency range $(30 \mathrm{MHz}-300 \mathrm{GHz})$. The other source is the ELF electromagnetic radiation $(0 \mathrm{~Hz}-100$ $\mathrm{kHz})$ generated by many modern domestic electrical appliances and electrical wires. The result of this study shows that when people were in a standing posture, the average electric field intensity with indoor electric appliances turned on was much greater than that with indoor electrical appliances turned off. Accordingly we assume the turned-on electrical appliances, which operate at Chinese standard electric power frequency $(50 \mathrm{~Hz}-60$ $\mathrm{Hz}$ ), may generate extremely low frequency electromagnetic waves of certain intensity.

Since the late 1970s, questions have been raised whether adverse health consequences would result after exposure to the extremely low frequency (ELF) electric and magnetic fields (EMFs). The biological effects from acute exposure at high levels (well above $100 \mu \mathrm{T}$ ) are 


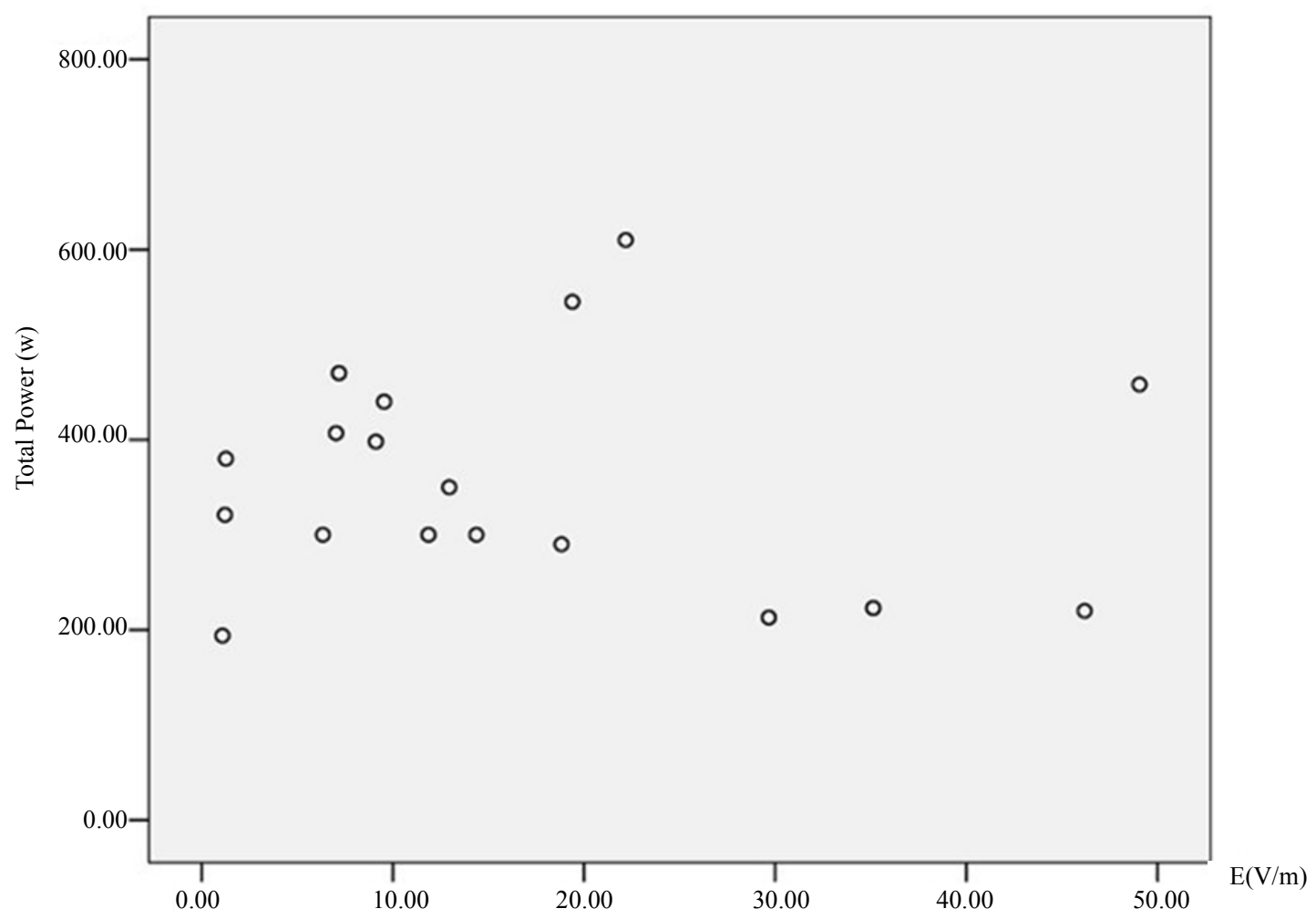

Figure 2. The scatter plot of total power of indoor electric appliances (W) versus electric field intensity (V/m) measured in standing posture $(5 \mathrm{~Hz}-1 \mathrm{kHz}), r=0.07, P>0.05$.

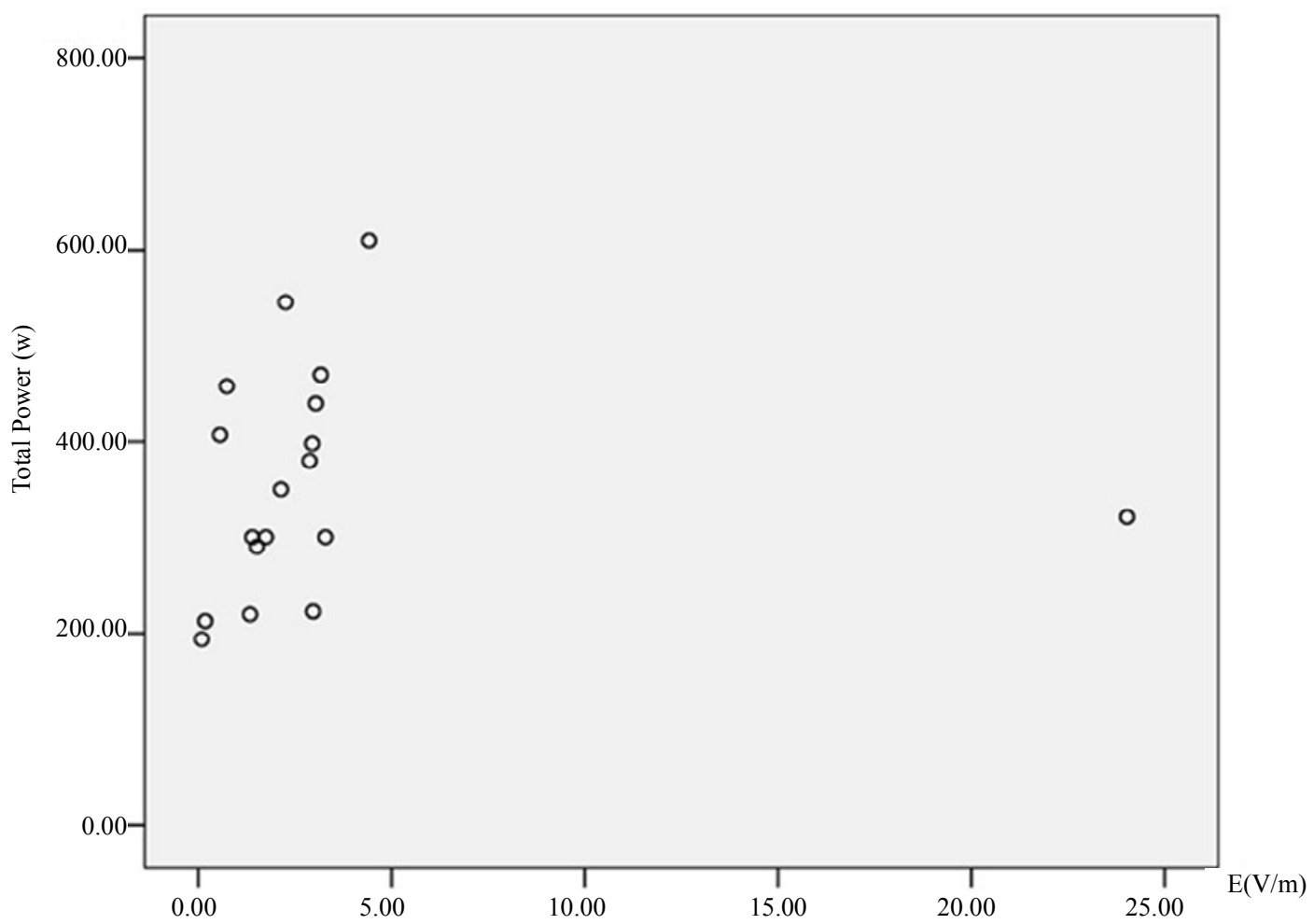

Figure 3. The scatter plot of the total power (W) of indoor electric appliances versus electric field intensity (V/m) measured in sitting posture (5 Hz $-1 \mathrm{kHz}), r=0.047, P>0.05$. 

Up-to-Now Still within the Range

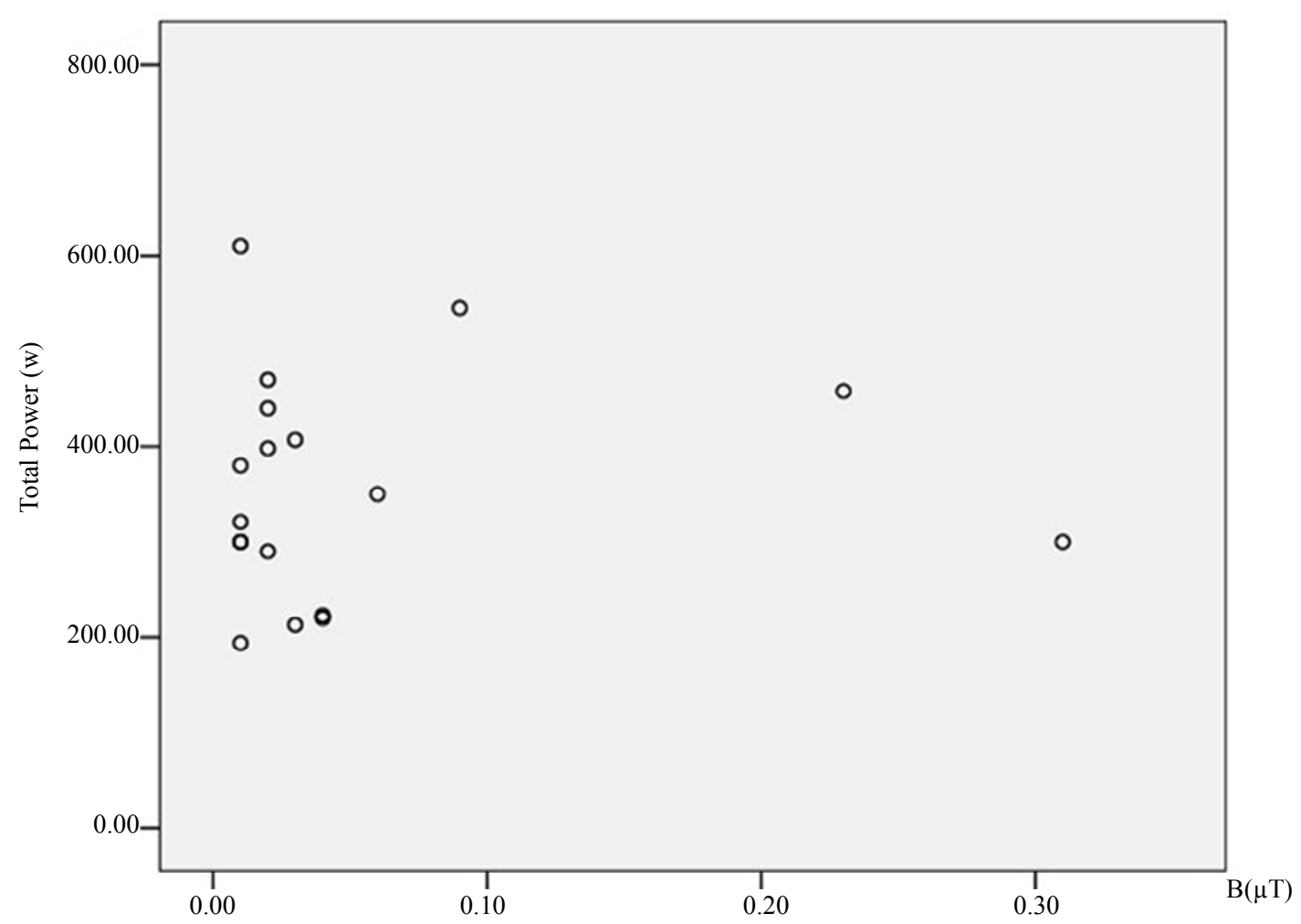

Figure 4. The scatter plot of the total power $(W)$ of indoor electric appliances versus magnetic flux intensity $(\mu T)$ measured In standing posture $(5 \mathrm{~Hz}-1 \mathrm{kHz}), r=0.072, P>0.05$.

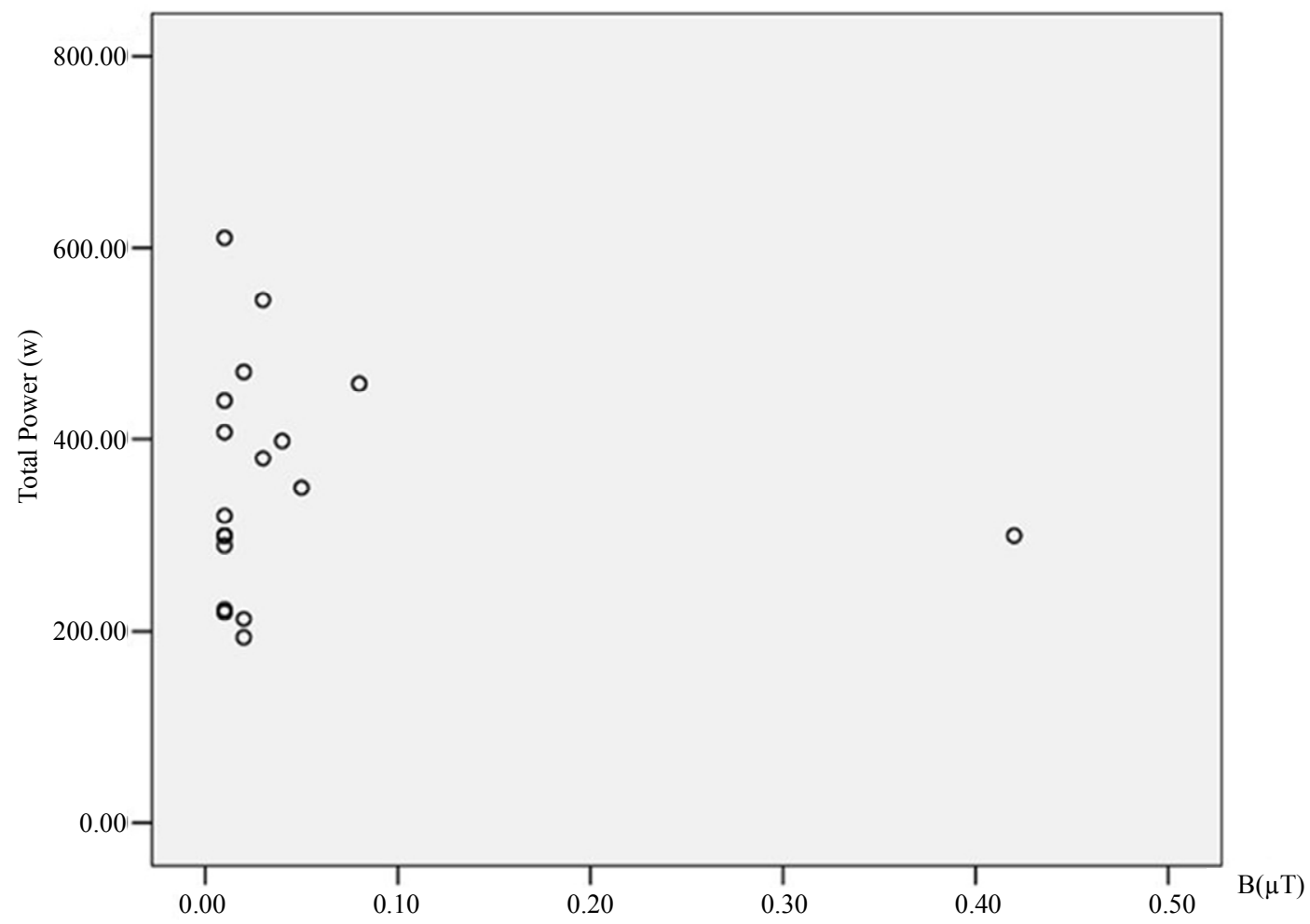

Figure 5. The scatter plot of the total power $(W)$ of indoor electric appliances versus magnetic flux intensity $(\mu T)$ measured in sitting posture (5 Hz - $1 \mathrm{kHz}$ ), $r=0.067, P>0.05$. 
well established and explained by recognized biophysical mechanisms. However, since external ELF magnetic fields can induce electric fields and currents in the body, thus exposure to the ELF magnetic fields of high intensity may change the excitability of the nerve cells in the central nervous system. Much of the scientific researches examining long-term risks from exposure to ELF magnetic field have focused on childhood leukemia. The pooled analyses of epidemiological studies have consistently demonstrated that a two-fold increase in childhood leukemia is associated with an average exposure at intensity of residential power-frequency above $0.3-0.4 \mu \mathrm{T}$. However, the causal relationship has yet to be convinceingly established by data related to childhood leukemia [9].

This investigation has raised the following questions that warrant further studies and/or analyses:

1) No single but multiple electromagnetic waves of various frequency ranges were present in the same indoor environment at different intensities. Although the measured values at every frequency range were below the ICNIRP reference level, further studies are necessary to ascertain whether the value of all frequency ranges superimposed collectively exceeds, or whether the superimposed field would lead to adverse health conesquences.

2) Both domestic and international electromagnetic radiation safety standards are established only for the known health hazards resulted from short-term electromagnetic radiation exposure. However, electromagnetic radiation existing in the modern residential environment, particularly in the indoor environment, will subject the occupants to a long-term exposure whose potential deleterious effects are yet to be determined. Accordingly, establishing the long-term exposure standards for electromagnetic radiation takes on a heightened urgency.

3) The measured values presented in this paper showed no correlation whatsoever between ELF fields and the total power of indoor electrical appliances. But in theory, the higher the power of the radiation source is, the greater the intensity of the electromagnetic radiation becomes. Furthermore, different manufacturing technologies and materials used by different manufacturers can also exert an influence on the value of electromagnetic radiation.

Therefore, aiming to address the potential health hazards that surfaced in this study, we offer the following advices on minimizing indoor electromagnetic radiation:

1) Avoid placing household electrical appliances in close proximity to each other.

2) Avoid using two or more electrical appliances simultaneously.

3) Minimize the frequency and duration of using elec- trical appliances as much as possible. Switch them off when they are not in use.

4) Maintain a certain distance from electrical appliances when they are turned on [10].

5) Use low-power appliances and qualified products made by established manufacturers to save electricity and reduce the electromagnetic radiation.

\section{Acknowledgements}

This study was supported by the grant from The Key Laboratory of Medical Protection for Electromagnetic Radiation, Ministry of Education of China and Natural Science Foundation of Chongqing, (Grant CSTC: 2007BB5303).

\section{REFERENCES}

[1] Z. O. I. Alhekail, "Electromagnetic Radiation from Microwave Ovens," Journal of Radiological Protection, Vol. 21, No. 3, 2001, pp. 251-258. doi:10.1088/0952-4746/21/3/303

[2] M. D. Taurisano and A. V. Vorst, "Experimental Thermographic Analysis of Thermal Effects Induced on a Human Head Exposed to $900 \mathrm{MHz}$ Fields of Mobile Phones," IEEE Transactions on Microwave Theory and Techniques, Vol. 48, No. 11, 2000, pp. 2022-2032. doi:10.1109/22.884191

[3] L. Hardell, M. Carlberg and K. H. Mild, "Case-Control Study of the Association between the Use of Cellular and Cordless Telephones and Malignant Brain Tumors Diagnosed during 2000-2003," Environmental Research, Vol. 100 , No. 2, 2006, pp. 232-241. doi:10.1016/j.envres.2005.04.006

[4] J. M. Elwood, "A Critical Review of Epidemiologic Studies of Radio Frequency Exposure and Human Cancers," Environmental Health Perspectives, Vol. 107, No. 1, Suppl. 1, 1999, pp. S155-S168. http://www.jstor.org/stable/3434480

[5] E. VanWijngaarden, D. A. Savitz, R. C. Kleckner, J. Cai and D. Loomis, "Exposure to Electromagnetic Fields and Suicide among Electric Utility Workers: A Nested Case -Control Study," Occupational Environmental Medcine, Vol. 57, No. 4, 2000, pp. 258-263. doi:10.1136/oem.57.4.258

[6] E. Hanada, K. Takano, Y. Antoku, K. Matsumura, Y. Watanabe and Y. Nose, "A Practical Procedure to Prevent Electromagnetic Interference with Electronic Medical Equipment," Journal of Medical System, Vol. 26, No. 1, 2002, pp. 61-65. doi:10.1023/A:1013094904976

[7] M. Havas. "Biological Effects of Non-ionizing Electromagnetic Energy: A Critical Review of the Reports by the US National Research Council and the US National Institute of Environmental Health Sciences as They Relate to the Broad Realm of EMF Bioeffects," Environmental Review, Vol. 8, No. 3, 2000, pp. 173-253. doi:10.1139/a00-004 
[8] H. S. Ge and M. Xie, "Study on Influence of Space Electric Field on Indoor Electromagnetic Distribution," Chinese Journal of Public Health Engineering, Vol. 4, No. 4, 2005, pp. 200-202.

[9] "Electromagnetic Fields and Public Health," Accessed 6 July 2010. http://www.who.int/mediacentre/factsheets/fs304/en/inde $\mathrm{x} . \mathrm{html}$

[10] "Typical Exposure Levels at Home and in the Environment," Accessed 6 July 2010.

http://www.who.int/docstore/peh-emf/publications/What is_EMF/section $4 . h t m$ 